\title{
A Comparative Study on The Existing Graphical User Interfaces for Occupational Therapy
}

\author{
Maryam Tayefeh Mahmoudi \\ Multimedia Research Group, IT Research Faculty \\ Research Institute for ICT \\ Tehran, Iran \\ mahmodi@itrc.ac.ir \\ Kambiz Badie \\ Knowledge Management \& e-Organization Group \\ IT Research Faculty, Research Institute for ICT \\ Tehran, Iran \\ $\underline{\text { K_badie@itrc.ac.ir }}$ \\ Shahab Hossein Ahmadi Varnousfaderani \\ Department of Surveying Engineering \\ Faculty of Engineering, University of Tehran \\ Tehran, Iran \\ shahab_hossein@ut.ac.ir
}

\begin{abstract}
In this paper, we present a comparative study on the existing graphical user interfaces (GUIs) as well as software application peculiarities used for occupational therapy. In our approach we make use of the peculiarities belonging to GUIs themselves and the corresponding software applications. Here, a tabular form is used to show the functionalities of the existing GUIs in association with the corresponding peculiarities. Through the comparative study, an opportunity is gained to build a hybrid strategy for designing GUIs that can function in case of patients with mixed disorders. This is quite interesting since many patients are in fact suffering from a combination of disorders.
\end{abstract}

Keywords - Graphical user interface (GUI); software application peculiarities; occupational therapy; physical disorder; mental disorder; tabular form; functionality.

\section{INTRODUCTION}

In recent years, Graphical User Interfaces ( GUIs) have been widely used in a wide range of Human Computer Interaction issues in the realms of education \& research, decision-making, idea/art creation, medical diagnosis \& treatment, movement/ posture control, etc. $[1,2,3,4]$. The point significant in all these cases is facilitating human computer interaction/ communication with the aim of guiding a computer and its peripheral systems in a direction compatible with the user's objectives. This means that, on the one side, computer should understand well what a user is intending, and on the other side, based on this understanding presents its decision to the user in terms of some messages or actions.

Among the issues calling for GUI, movement/ posture control in the disabled or patients with movement disorders is of particular significance. It is easily seen that, the message provided by GUI in this case, has the ability to give the patient an idea on how to select his/ her posture as well as control mental disorder. In this way, developing GUIs based on the features of disabilities or disorders, may achieve a fruitful role in minimizing patient's stress/ anxiety, and besides that increasing the efficiency of the related treatment $[4,5]$. Due to significance of such a notion, in this paper, we decided to make a comparative study on a variety of GUIs already developed for treating movement disorders, to figure out what peculiarities should exist in a GUI to make it most fittble for certain pathological situations. It is to be noted that, due to the difference in cognitive/ affective preferences of different patients with different types of disorders, the corresponding GUIs should be benefited by different peculiarities [6,7]. That is the main point we are trying to crystallize in this paper.

\section{RELATED WORKS}

There has been a growing interest in using technology platforms and software applications for training purposes in physical or mental occupational therapy. In these assisting software packages, the component which has a significant role in attracting audiences is Graphical User Interface (GUI). 
ICIT 2015 The $7^{\text {th }}$ International Conference on Information Technology

doi:10.15849/icit.2015.0104 @ ICIT 2015 (http://icit.zuj.edu.jo/ICIT15)

Different perspectives may affect GUI design, such as: aesthetics, pedagogy, user-friendliness, cultural appropriateness, accessibility, effectiveness, engagement and innovation, etc. [8,9]. Beside the above-mentioned perspectives, in the case of Occupational Therapy, for those patients, their caregivers or therapists, who may not be able or familiar enough to apply those software packages, some other considerations may also be added. For instance, the GUI should be "simple", "user in control" and "consistent" to motivate the patient or his/her caregivers for continuous use.

Existing research activities in the domain of occupational therapy, reveals that mental-assisting software tools have a history longer than physical ones. The most feasible example of using such tools returns to supporting social and selfmanagement skills in children with Autistic Spectrum Disorders (ASD), for which there is a burgeoning progress of designing assistant applications. Some of these applications focus on improving complete tasks, as well as transition within and between tasks [10]. While, the others present standardized measurement tools to estimate PDA's efficiency as cognitive assistants [11]. It is mentionable that, in addition to applications for patients, there also exist some applications for parents and instructors (ex. "HANDS") to train them how to assist the patients [12]. Also, in last years numerous mobile applications have been designed to help patients, suffering from autism including: "iOT session" [13], "Shelby's Quest" [14], "Brain Works" [15], "Autism Learning Games Camp Discovery" [16], and "Find me" [17], etc..

Another field of exploiting technology for mental therapy is assisting individuals with moderate-to-severe memory impairment, for which extensive fields of research have been done including: supporting memory function in individuals with milder memory impairment using mobile phones [18, 19], digital voice recorders [20] and PDAs and smart phones [21,

22]. In all these studies, the role of caregivers is crucial specifically in the cases where patients are unable to program the reminders, calendars and troubleshooting parts. Although, the first suggestion has been on structured training to make patients independent in using PDAs $[23,24,25,26]$, this suggestion is however not adequate for patient with severe memory impairment [26, 27]. Therefore a prosthetic memory protocol that teaches how to store and retrieve information in/ from a memory book, has been developed for patients with severe amnesia [28].

Beside the above-mentioned applications, there exist some software applications for other mental disturbances such as: depression, insomnia and anxiety. Some of the well-known related applications are: "Operation Reach Out" [29], "BellyBio" [30], "Optimism" [31], "iSleep Easy" [32], etc.

Moreover, physical disabilities have also been assisted by software applications in the present decade. For different types of pathological disorders, specific applications have been developed. For instance, "PT and OT helper"[33] and "Dexteria VPP"[34] are useful for fingers and hand exercises, while, "Occupational therapy" [35], "Therapy Boss" [36], "Physical Therapy Home exercises" [37] and "Physical Therapy for kids" [38], cover various parts of body exercise even for daily activities.

Taking the above points into account, the application and its graphical user interface should be designed using a variety of parameters (Fig.1), such as context, method, purpose, user and type to provide a wide range of facilities and potentials for conveying different types of context, accessibility, safety, diversity, and digestibility for all kinds of users with different mental or physical disorders.

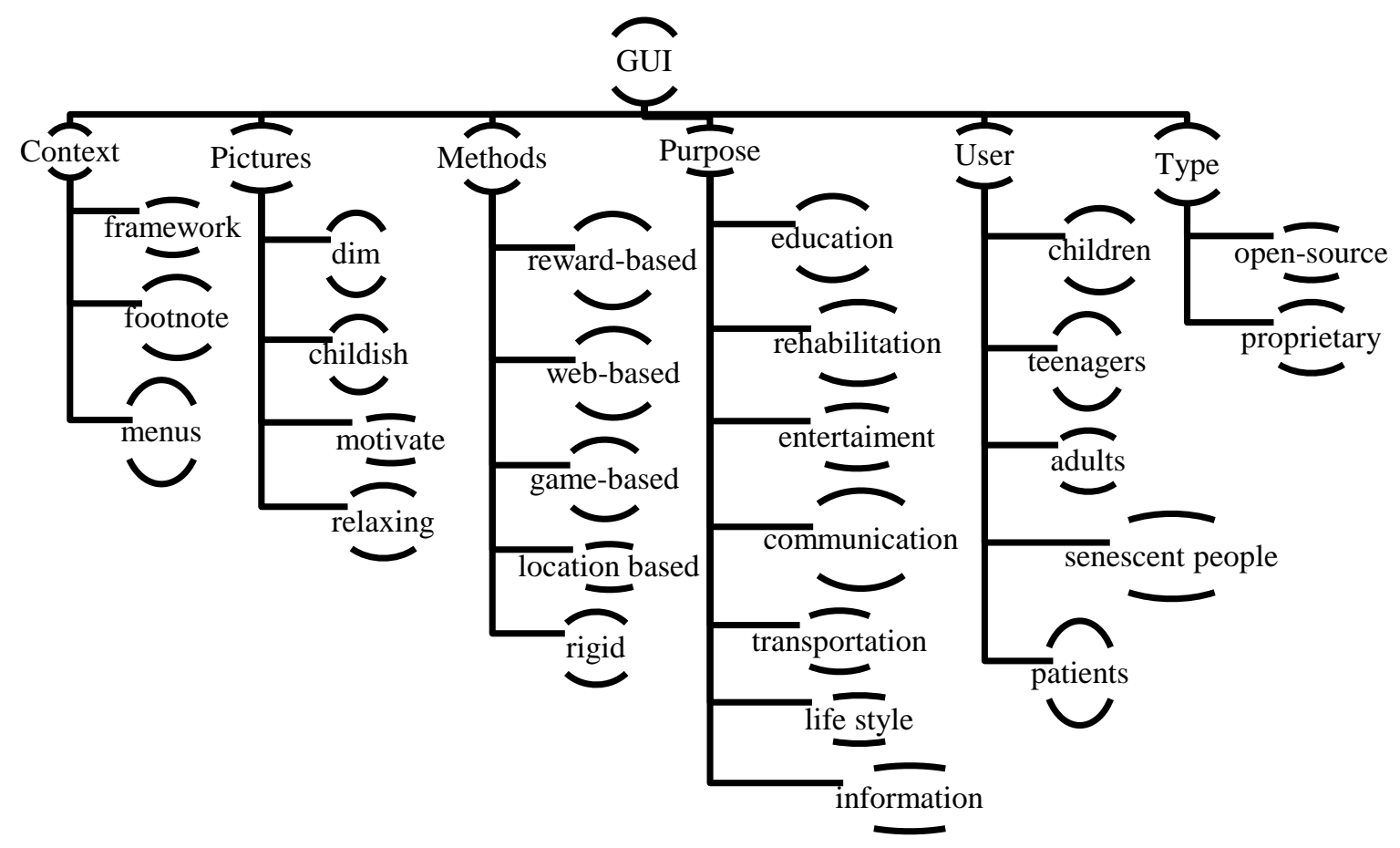


Role of different kinds of learning methodologies such as micro learning [39], game-based learning [40], location-based learning [41], and ICT-based learning [42] in reinforcing the patients to overcome their barriers, should not be disregarded in this respect. In addition to the above-mentioned parameters, there also exit some software and GUI peculiarities which play a significant role in designing appropriate assisting applications in this domain. These may not only attract users, but also facilitate their exercises. In this paper, we would like to have a comparative study on these parameters within the existing applications

\section{SIGNIFICANT PECULIARITIES OF THE EXISTING SOFTWARES AS WELL AS THEIR GUI}

Graphical User Interface (GUI) achieves a high role in facilitating communication between the system on the one side and the therapist or the patient on the other side. GUIs should therefore be designed in a way that such goals can be achieved most plausibly. To approach understanding what certain protocols should be considered in designing an optimal GUI, it should first be studied how the existing GUIs holding certain software peculiarities have in practice behaved toward the corresponding pathological disorders, and how these peculiarities can in turn be responsible for achieving the related success or failure. It should then be analyzed, based on the existing learning theories, how these considerations can be justified from epistemological viewpoint. What we have done in our approach, is to conduct such a study.

To conduct our comparison, we first need some significant peculiarities both for "software" and "GUI", based on which such entities can be characterized. To specify such peculiarities we first referred to some existing resources (including both accreditation websites and research papers) discussing the capabilities of the entities, and then out of the peculiarities mentioned for them, we selected those items which were believed to be of high significance for the area of Occupational Therapy through Mobile Applications [3, 4, 9, 13, 14, 15, 16, $17,30,31,32,33,34,35,36,37,38,43]$. Within the process of selection, we paid mostly attention to those peculiarities which of least correlation in a thematic sense. We finally ended up with those elaborated in Table I.

Since GUI's peculiarities are hardly understandable, below we give a brief definition of them:

- User in Control: This master key has an undeniable role in the GUI efficiency, which mentions that users should have the authority of controlling the software behavior (for instance asking for users' confirmation for every vital command like "Quit", "Delete", and so on), as well as altering parts of interface in order to customize the GUI based on their own needs, skills, and habits.

- Directness: Users should be directed to their purpose through the shortest path, and by the minimal set of tasks in order to become able of retouching GUI objects in the most direct manner.(allowing users to make shortcuts is the most common example of directness).

- Consistency: A GUI should be well-known and predictable for all sorts of users, who have been adapted to other software products so far. Therefore all facets of the GUI including labels, layout, behavior,... should be compatible with other software products' GUI in order to reduce the learning process of the software, and makes agile its adoption (objects dragging function in all standard smart phones is the same, according to which users should hold their finger on the object and move the object to their favorable place without removing their finger).

- Forgiveness: This peculiarity leads developers to make users' actions reversible and recoverable. Therefore users do not have to start from the first step once a mistake has occurred in the processes of choosing, typing, deleting, or even closing a window. The purpose of forgiveness is to allow users to become familiar with the software, and learn how to use it gradually (Recycle bin, where deleted objects are able to be restored is an example of "Delete" function forgiveness).

- Feedback: This maxim has a close relevance to the user in control peculiarity as though users should be provided with immediate visual response to their actions, which allows them to understand which processes are being executed (If the user has deleted an object, he/she should then immediately feel that the object does not exist anymore).

- Aesthetics: is proved to be the most discernible aspect of GUIs' design, since it is the first layer which is presented to users. Aesthetics peculiarities are proportion, symmetry, color, lines, texture, balance, flow, ..., which have a crucial role in attracting users, and can affect users' behavior and cognitive processes as well in visual facet; harmony is believed to depend on an appropriate arrangement of different fragments which leads finally to a pleasant perception by eyes (There have been lots of software products led to failure due to overlooking aesthetics aspects even though they have been rich in other aspects).

- Simplicity: A user interface should not be complicated to use and to learn either, because the more a GUI is designed simply and directly around what its users demand, the more success the system will gain. On the other hand, in order to optimize simplicity, developers should benefit from a type of prior knowledge about targeted users' level of education, age, gender, and purpose so as to provide the apt level of complexity (A comparison between Yahoo and Google represents the significance of simplicity in attracting users).

All kinds of mobile applications are somehow trying to teach a concept to the users. The concept can be even how to use the application. Therefore all of mobile applications should have been designed based on a learning theory. There are lots of learning theories which have been used in favor of different purposes, and in different styles such as "Behavioral Learning Theory", "Cognitive Learning Theory", "Information Processing Learning Theory" and "Constructive Learning Theory" [44, 45]. So learning theories should be elicited in 
ICIT 2015 The $7^{\text {th }}$ International Conference on Information Technology

doi:10.15849/icit.2015.0104 C ICIT 2015 (http://icit.zuj.edu.jo/ICIT15)

order to be recognized in applications. Here are the characteristics of some widespread learning theories, based on which mobile applications make sense.

\section{FACTS DERIVED THROUGH THE COMPARATIVE STUDY WITH RESPECT TO THE SOFTWARES USED}

Looking at the content of Table I, the following facts seem to be consistent:

- "Reminders" with both mental and physical applications, are useful for the patients, who may forget to use the application, or for therapists who probably have more than one patient. Therefore smart schedules (or in other words reminders) as well as "consistency" are mandatory in GUI peculiarities, because these sorts of applications have been designed for long term usages, in a way that all features should be consistent in order to optimize the rehabilitation process.

- "Patients location records" have manifested only in some applications, for mental therapy. As the patients may get lost, location records are thus believed to be extremely helpful in these cases.

- "Exercise management" has been presented chiefly in physical and occupational therapy applications due to the intense requirement of exercises stability. Here "Consistency" has a promising role, because sporadic and unorganized exercises are harmful for the patient in the sense of decelerating the rehabilitation process.

- "Patients records" has mostly appeared in those applications, that try to produce a report of the rehabilitation or treatment process. This is to help therapists and doctors to find out how much the patient is in trying mode, what strengths and weaknesses he/she has, and whether the application is helpful or not. Therefore the application should lead the patient as directedly as possible in order to optimize this procedure. Due to this "Directness" has been considered effectively in GUI peculiarities.

- "Activity monitoring" is apparently similar to "Patient records", but the reason of separation lies in the variation of those activities done by the patients which cannot be considered as patient records. Particularly, in mental applications activity, monitoring is much more required than patient records, because in mental cases the treatment reports are usually produced implicitly when the patient is working with the application. The other point is that "Activity monitoring" is mandatory for applications that are based on "Constructive" learning theory, let say those which are game-based. These kinds of applications have mainly obtained a high grade of "Simplicity" in order to avoid any complication in the procedure of using the application for those patients who are not as intelligent as the normal people.

- "Audio instructions" and "Written instructions" have manifested mostly in physical and mental therapy applications in order to increase digestibility of

instructions given by the application. In the meantime, with regard to some mental cases, they have been presented in a musical way in order to tranquilize the patient. In this way, "atheistic" has been shown to be very effective for this purpose.

Besides the above facts we also noticed some other points with regard to relations between GUI's peculiarities and types of disability as follows:

- GUIs used for patients with mental disorders, and those having disability in hand and fingers, is required to be more "simple" mainly because of limitation in their ability to interact mentally with the surrounding environment.

- $\quad$ For patients with mental problems like Autism, "Aesthetic Aspects" are believed to be more important simply because such patients may need more attention compared to other patients.

- For patients with mental disorders, who suffer from visual tracking and insomnia, "Feedback" and "Forgiveness" aspects are necessary to promote for continuous practice.

- GUIs used for patients with physical disorders, especially with disability in hand area, should be "Consistent". That is because patients have got used to some software's facets and we should facilitate their reactions with minimum learning efforts.

- For patients with mental problems, who need to concentrate on writing skill and visual tracking, "Directness" and "User in control" are two significant aspects which can navigate the patient directly and personalize software for easy use.

- The most important aspects for physical disorders are "Consistency" and "Simplicity" which have to be considered in GUI design.

From the point of learning theory considerations, it is mentionable that, majority of software applications listed in Table I, control the progress trend of patient, by his/her behavior and actions. Thus, most of them have been constructed based on "Behaviorism". There however exist some applications mostly for mental problems which actually engage the patient and ask him/ her to write a text or draw a painting. In these cases, the applications are benefitted from "Constructivism" learning theory. The other kinds of learning theories have not been observed in the applications which have been investigated in Table I.

\section{CONCLUSION}

In the paper a comparative study was done on the existing GUIs for the patients with a variety of physical as well as mental disorders. Comparison was based on the peculiarities belonging to GUIs themselves and the softwares used for them to make them respond effectively. A tabular form was made in this regard to show the functionalities of the existing GUIs in association with the corresponding peculiarities. It was seen that, for mental disorders such as autism wherein patients are tremendously introvert and thus have slight feeling for interaction with their environment, GUIs holding peculiarities 
ICIT 2015 The $7^{\text {th }}$ International Conference on Information Technology

doi:10.15849/icit.2015.0104 @ ICIT 2015 (http://icit.zuj.edu.jo/ICIT15) such as "Aesthetics", "Feedback", or "Forgiveness" are suggested. While for disorders in writing skills and visual tracking, the patient prefers to make use of GUIs with peculiarities such as "Directness" and "User in control". Taking such points into account, one may gain the opportunity to build a hybrid strategy for designing GUIs that can function in case of patients with mixed disorders. This is quite interesting since many patients are in reality suffering from a combination of disorders each having his/her own complication with regard to the format of interaction and thereby the GUI to be used. Developing such a hybrid strategy can be regarded as a promising future work for therapeutic mobile applications.

\section{REFERENCES}

[1] K. Bazargan Harandi (2011). Abstract Information Visualization in Interactive 3D Virtual Environments: Conceptualization and Usability Evaluation. Thèse de doctorat: Université de Genève, 2011, no. SES 747, Edition SES - Université de Genève, ISBN 978-2-88903-005-7.

[2] H. E. Moore IV, O. Andlauer, N. Simon, E. Mignot, "Exploring medical diagnostic performance using interactive, multi-parameter sourced receiver operating characteristic scatter plots," Computers in Biology and Medicine, vol. 47, pp. 120-129, 1 April 2014.

[3] Ž. Mijailović, D. Milićev, "Empirical analysis of GUI programming concerns," International Journal of Human-Computer Studies, vol. 72, issues 10-11, pp. 757-771, October-November 2014.

[4] Y. B. Salman, H. I. Cheng, P. E. Patterson, "Icon and user interface design for emergency medical information systems: A case study," International Journal of Medical Informatics, vol. 81, issue 1, pp. 29-35, January 2012.

[5] C.T. Asque, A.M. Day, S.D. Laycock, "Augmenting graphical user interfaces with haptic assistance for motion-impaired operators," International Journal of Human-Computer Studies, vol. 72, issues 1011, pp. 689-703, October-November 2014.

[6] J. M. Schraagen, F. Verhoeven, "Methods for studying medical device technology and practitioner cognition: The case of user-interface issues with infusion pumps," Journal of Biomedical Informatics, vol. 46, Issue 1, pp. 181-195, February 2013.

[7] S. Mazzoleni, M. Munih, A. Toth, J. Cinkelj, M. Jurak, J. V.Vaerenbergh, G. Cavallo, P. Soda, P. Dario, E. Guglielmelli, "Wholebody isometric force/torque measurements for functional assessment in neuro-rehabilitation: User interface and data pre-processing techniques," Computer Methods and Programs in Biomedicine, vol. 110, issue 1, pp.27-37, April 2013.

[8] D. J. Brown, D. McHugh, P. Standen, L. Evett, N. Shopland, S. Battersby, "Designing location-based learning experiences for people with intellectual disabilities and additional sensory impairments," Computers \& Education, vol. 56, pp.11-20, 2011.

[9] Microsoft Corporation Staff, The Windows Interface Guidelines for Software Design, Microsoft Press, 2 edition, January 1, 1994.

[10] L. C. Mechling, and E. J. Savidge, "Using a personal digital assistant to increase completion of novel tasks and independent transitioning by students with autism spectrum disorder, " Journal of Autism Developmental Disorders, vol. 39, no. 10, pp. 1420-1434, 2009.

[11] T. Gentry, J. Wallace, C. Kvarfordt, and K. B. Lynch, "Personal digital assistants as cognitive aids for high school students with autism: results of a community-based trial," Journal of Vocational Rehabilitation, vol. 32, pp. 101-107, 2010.

[12] J. Mintz, C. Branch, C. March, and S. Lerman, "Key factors mediating the use of a mobile technology tool designed to develop social and life skills in children with Autistic Spectrum Disorders," Computers \& Education, vol. 58, pp. 53-62, 2012.

[13] iOT Session, www.iot-session.com

[14] Shelby's Quest, www.doodletherapyapps.com

[15] Brain works, www.sensationalbrain.com

[16] Autism www.campdiscoveryforautism.com

[17] Find me, www.interface3.com/findme

[18] S. Stapleton, M. Adams, and L. Atterton, "A mobile phone as a memory aid for individuals with traumatic brain injury: A preliminary investigation," Brain Injury, vol. 21, no. 4, pp. 401-411, 2007.

[19] T. K. Wade, and J. C. Troy, "Mobile phones as a new memory aid: A preliminary investigation using case studies," Brain Injury, vol. 15, no. 4, pp. 305-320, 2001.

[20] T. Hart, K. Hawkey, and J. Whyte, "Use of a portable voice organizer to remember therapy goals in traumatic brain injury rehabilitation: A within subjects trial," Journal of Head Trauma Rehabilitation, vol. 17, no. 6, pp. 556-570, 2002.

[21] H. J. Kim, D. T. Burke, M. M. Dowds, K. A. R. Boone, and G. J. Park, "Electronic memory aids for outpatient brain injury: Follow-up findings," Brain Injury, vol. 14, no. 2, pp. 187-196, 2000.

[22] H. J. Kim, D. T. Burke, M. M. Dowds, and J. George, "Case study: Utility of a microcomputer as an external memory aid for a memoryimpaired head injury patient during in-patient rehabilitation," Brain Injury, vol. 13, no. 2, pp. 147-150, 1999.

[23] J. M. Fleming, D. Shum, J. Strong, and S. Lightbody, "Prospective memory rehabilitation for adults with traumatic brain injury: A compensatory training program me," Brain Injury, vol. 19, no. 1, pp. 113, 2005.

[24] T. Gentry, "PDAs as cognitive aids for people with multiple sclerosis," American Journal of Occupational Therapy, vol. 62, no. 1, pp. 8-27, 2008.

[25] T. Gentry, J. Wallace, C. Kvarfordt, and K. B. Lynch, "Personal digital assistants as cognitive aids for individuals with severe traumatic brain injury: A community-based trial," Brain Injury, vol. 22, no. 1, pp. 1924, 2008.

[26] G. M. Giles, and M. Shore, "The effectiveness of an electronic memory aid for a memory impaired adult of normal intelligence," American Journal of Occupational Therapy, vol. 43, no. 6, 1989, pp. 409-411.

[27] B. A. Wilson, A. D. Baddeley, and J. M. Cockburn, "How do old dogs learn new tricks: Teaching a technological skill to brain injured people," Cortex, vol. 25, pp. 115-119, 1989.

[28] B. Richards, L. Leach, and G. Proulx, "Memory rehabilitation in a patient with bilateral dorsomedial thalamic infarcts," Journal of Clinical and Experimental Neuropsychology, vol. 12, pp. 395, 1990.

[29] Operation Reach Out, www.militaryfamily.com/downloads/apps Imilitary-suicide-prevention-operation-reach-out/

[30] BellyBio, www.bellybio.com

[31] Optimism, www.findingoptimism.com

[32] iSleep Easy, www.meditationoasis.com/smartphone-apps/iphoneapplication-support/isleep-easy-free-app-support

[33] PT and OT helper, www.ptandot-helper.com

[34] Dexteria VPP, www.dexteria.net

[35] Occupational therapy, www.angelfire.com/me/xutm

[36] Therapy Boss, www.pragmait.com

[37] Physical Therapy Home Exercises, www.facebook.com/pages/PTGenie

[38] Physical Therapy for Kids, https://itunes.apple.com/us/app/physicaltherapy-for-kids/id $923005281 ? \mathrm{mt}=8$

[39] T. Hug, Didactics of microlearning: Concepts, discourses and examples. Munster. Waxmann Verlag, 2007.

[40] M. A. Hersh, and B. Leporini, Accessibility and usability of educational games for disabled students. In C. Gonzalez (Ed.), Student usability in educational software and games: Improving experiences, IGI Global, 2012, pp. 1-40.

[41] D. J. Brown, D. McHugh, P. Standen, L. Evett, N. Shopland, and S. Battersby, "Designing location-based learning experiences for people with intellectual disabilities and additional sensory impairments," Computers \& Education, vol. 56, pp. 11-20, 2011.

[42] M. Hersh, "Evaluation framework for ICT-based learning technologies for disabled people," Computers \& Education, vol. 78, pp. 30-47, 2014. 
ICIT 2015 The $7^{\text {th }}$ International Conference on Information Technology

doi:10.15849/icit.2015.0104 C ICIT 2015 (http://icit.zuj.edu.jo/ICIT15)

[43] M. Zen, "Metric-Based Evaluation of Graphical User Interfaces: Model,

Method, and Software Support," The Fifth ACM SIGCHI Symposium

on Engineering Interactive Computing Systems (eics2013), UK, June 24-27, 2013.

[44] A. Saif, Modern Educational Psychology, Doran Pub., 2010.

[45] P. Kadivar, Psychology of Learning, Samt Publication, 2010. 
TABLE I. OCCUPATIONAL THERAPY APPLICATION'S PECULIARITIES

\begin{tabular}{|c|c|c|c|c|c|c|c|c|c|c|c|c|c|c|c|c|c|c|c|c|c|c|c|c|c|}
\hline \multirow{3}{*}{$\begin{array}{c}\text { Name of Software } \\
\text { for } \\
\text { Occupational } \\
\text { Therapy }\end{array}$} & \multicolumn{14}{|c|}{ Software Peculiarities } & \multicolumn{7}{|c|}{ GUI Peculiarities } & \multicolumn{3}{|c|}{ Type of Disability } & \multirow{3}{*}{$\begin{array}{c}\text { Learning } \\
\text { Theory } \\
\text { Considerations }\end{array}$} \\
\hline & \multirow{2}{*}{ 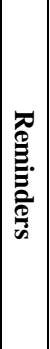 } & \multirow{2}{*}{ 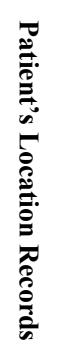 } & \multirow{2}{*}{ 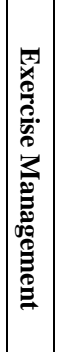 } & \multirow{2}{*}{ 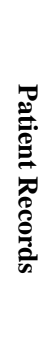 } & \multirow{2}{*}{ 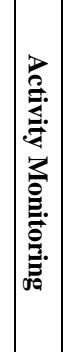 } & \multirow{2}{*}{ 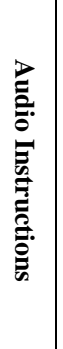 } & \multirow{2}{*}{ 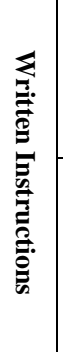 } & \multicolumn{3}{|c|}{ 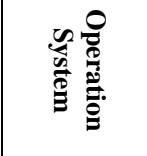 } & \multicolumn{2}{|c|}{ 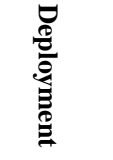 } & \multicolumn{2}{|r|}{$\stackrel{\mathscr{n}}{\vec{E}}$} & \multirow{2}{*}{ 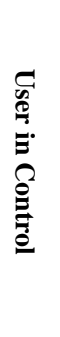 } & \multirow{2}{*}{ 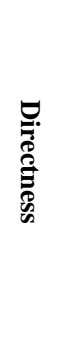 } & \multirow{2}{*}{ 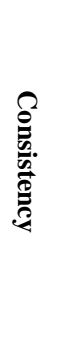 } & \multirow{2}{*}{ 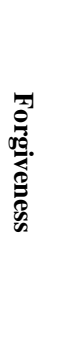 } & \multirow{2}{*}{ 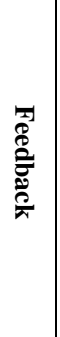 } & \multirow{2}{*}{ 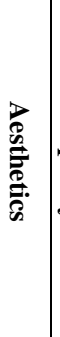 } & \multirow{2}{*}{ 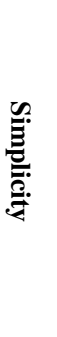 } & \multirow{2}{*}{$\begin{array}{c}\text { Physical } \\
\begin{array}{c}\text { Type of } \\
\text { Pathological } \\
\text { Disorder }\end{array}\end{array}$} & \multirow{2}{*}{$\begin{array}{c}\text { Mental } \\
\text { Type of } \\
\text { Mental } \\
\text { Disorder }\end{array}$} & \multirow{2}{*}{ 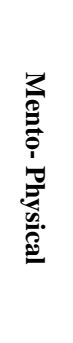 } & \\
\hline & & & & & & & & 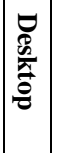 & $\bar{\sigma}$ & 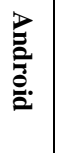 & 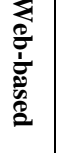 & 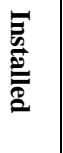 & 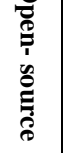 & 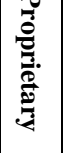 & & & & & & & & & & & \\
\hline $\begin{array}{l}\text { PT and OT helper: } \\
\text { Fingers Hand }^{(1)}\end{array}$ & $\checkmark$ & & $\checkmark$ & $\checkmark$ & & $\checkmark$ & $\checkmark$ & & $\checkmark$ & $\checkmark$ & $\checkmark$ & & & $\checkmark$ & M & M & $\mathrm{H}$ & $\mathrm{L}$ & M & M & $\mathrm{L}$ & Fingers and Hand & & & Behaviorism \\
\hline $\begin{array}{c}\text { PT and OT helper: } \\
\text { Ankle }^{(2)}\end{array}$ & $\checkmark$ & & $\checkmark$ & $\checkmark$ & & $\checkmark$ & $\checkmark$ & & $\checkmark$ & $\checkmark$ & $\checkmark$ & & & $\checkmark$ & M & M & $\mathrm{H}$ & $\mathrm{L}$ & M & M & $\mathrm{L}$ & Ankle & & & Behaviorism \\
\hline $\begin{array}{l}\text { PT and OT helper: } \\
\text { Elbow }^{(3)}\end{array}$ & $\checkmark$ & & $\checkmark$ & $\checkmark$ & & $\checkmark$ & $\checkmark$ & & $\checkmark$ & $\checkmark$ & $\checkmark$ & & & $\checkmark$ & M & M & $\mathrm{H}$ & $\mathrm{L}$ & M & M & $\mathrm{L}$ & $\begin{array}{c}\text { Elbow } \\
\text { (for tennis players and golf } \\
\text { players in two versions) }\end{array}$ & & & Behaviorism \\
\hline Dexteria VPP $^{(4)}$ & & & $\checkmark$ & $\checkmark$ & $\checkmark$ & & & & $\checkmark$ & $\checkmark$ & $\checkmark$ & & & $\checkmark$ & $\mathrm{H}$ & $\mathrm{H}$ & M & $\mathrm{L}$ & M & $\mathrm{H}$ & $\mathrm{H}$ & Fingers and Hand & & & Constructivism \\
\hline iOT Session ${ }^{(5)}$ & & & & $\checkmark$ & & & & & $\checkmark$ & & $\checkmark$ & & $\checkmark$ & & $\mathrm{L}$ & M & $\mathrm{H}$ & $\mathrm{L}$ & M & M & M & $\begin{array}{l}\text { Visual Perception, scanning, } \\
\text { Handwriting }\end{array}$ & \begin{tabular}{|c|} 
Autism, developmental \\
delays, learning disabilities, \\
ADHD
\end{tabular} & $\checkmark$ & Behaviorism \\
\hline $\begin{array}{c}\text { Occupational } \\
\text { Therapy }^{(6)}\end{array}$ & & & & & & & $\checkmark$ & & & $\checkmark$ & $\checkmark$ & & $\checkmark$ & & $\mathrm{L}$ & $\mathrm{L}$ & $\mathrm{H}$ & $\mathrm{L}$ & $\mathrm{L}$ & M & M & $\begin{array}{l}\text { Useful OT Instruments, } \\
\text { designed for daily activities }\end{array}$ & & & $\begin{array}{c}\begin{array}{c}\text { Behaviorism } \\
\text { and } \\
\text { Constructivism }\end{array} \\
\end{array}$ \\
\hline Therapy BOSS ${ }^{(7)}$ & $\checkmark$ & & $\checkmark$ & $\checkmark$ & & & & $\checkmark$ & $\checkmark$ & $\checkmark$ & & $\checkmark$ & $\checkmark$ & & M & M & M & M & M & $\mathrm{L}$ & M & $\begin{array}{l}\text { depends on the therapist } \\
\text { (can be used for } \\
\text { every parts) }\end{array}$ & & & Behaviorism \\
\hline Ask the OT ${ }^{(8)}$ & & & & & & $\checkmark$ & $\checkmark$ & & & $\checkmark$ & $\checkmark$ & & $\checkmark$ & & M & $\mathrm{L}$ & $\mathrm{L}$ & $\mathrm{L}$ & $\mathrm{L}$ & M & $\mathrm{H}$ & $\begin{array}{c}\text { Information hotspot about } \\
\text { OT, }\end{array}$ & & & $\begin{array}{l}\text { Behaviorism } \\
\text { and } \\
\text { Constructivism }\end{array}$ \\
\hline Shelby's Quest $^{(\mathbf{9})}$ & & & $\checkmark$ & $\checkmark$ & $\checkmark$ & & $\checkmark$ & & $\checkmark$ & & & $\checkmark$ & & $\checkmark$ & M & M & M & M & M & M & $\mathrm{H}$ & $\begin{array}{l}\text { Visual Perceptual Deficits, } \\
\text { finger isolation }\end{array}$ & $\begin{array}{c}\text { Autism, developmental } \\
\text { delays, fine motor delays, } \\
\text { AS and DS } \\
\end{array}$ & $\checkmark$ & Constructivism \\
\hline Ready to Print ${ }^{(10)}$ & & & $\checkmark$ & $\checkmark$ & & & & & $\checkmark$ & $\checkmark$ & & $\checkmark$ & & $\checkmark$ & M & M & M & $\mathrm{L}$ & M & M & $\mathrm{H}$ & $\begin{array}{l}\text { Visual Perceptual, Finger } \\
\text { isolation }\end{array}$ & $\begin{array}{l}\text { Fine motor skills, pre- } \\
\text { writing skills, } \\
\text { developmental delays }\end{array}$ & $\checkmark$ & Constructivism \\
\hline Brain Works $^{(11)}$ & $\checkmark$ & $\checkmark$ & $\checkmark$ & $\checkmark$ & $\checkmark$ & & & & $\checkmark$ & & $\checkmark$ & & & $\checkmark$ & M & $\mathrm{H}$ & $\mathrm{H}$ & M & $\mathrm{H}$ & M & $\mathrm{H}$ & & $\begin{array}{c}\text { sensory processing } \\
\text { disorders, Autism, ADHD, } \\
\text { ADD, learning disabilities }\end{array}$ & & Behaviorism \\
\hline Letter Reflex ${ }^{(12)}$ & & & $\checkmark$ & $\checkmark$ & $\checkmark$ & & & & $\checkmark$ & & $\checkmark$ & & & $\checkmark$ & $\mathrm{H}$ & $\mathrm{H}$ & M & $\mathrm{L}$ & M & $\mathrm{H}$ & $\mathrm{H}$ & & \begin{tabular}{c|} 
Writing skills, letter \\
reversal \& backwards \\
recognition
\end{tabular} & & Constructivism \\
\hline
\end{tabular}


ICIT 2015 The $7^{\text {th }}$ International Conference on Information Technology doi:10.15849/icit.2015.0104 C ICIT 2015 (http://icit.zuj.edu.jo/ICIT15)

\begin{tabular}{|c|c|c|c|c|}
\hline Name of Software & Software Peculiarities & GUI Peculiarities & Type of Disability & $\begin{array}{c}\text { Learning } \\
\text { Theory }\end{array}$ \\
\hline
\end{tabular}


ICIT 2015 The $7^{\text {th }}$ International Conference on Information Technology

doi:10.15849/icit.2015.0104 C ICIT 2015 (http://icit.zuj.edu.jo/ICIT15)

\begin{tabular}{|c|c|c|c|c|c|c|c|c|c|c|c|c|c|c|c|c|c|c|c|c|c|c|c|c|c|}
\hline & \multirow{2}{*}{ 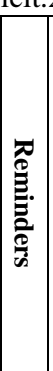 } & \multirow{2}{*}{ 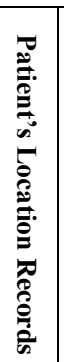 } & \multirow{2}{*}{ 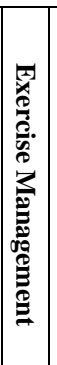 } & \multirow{2}{*}{ 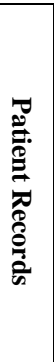 } & \multirow{2}{*}{ 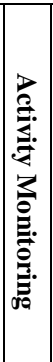 } & \multirow{2}{*}{ 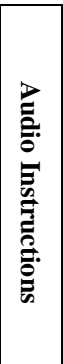 } & \multirow{2}{*}{ 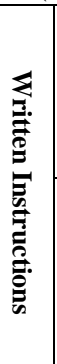 } & \multicolumn{3}{|c|}{ 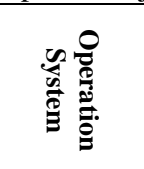 } & \multicolumn{2}{|c|}{ 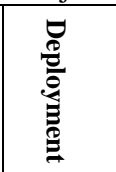 } & \multicolumn{2}{|r|}{$\frac{n}{\vec{*}}$} & \multirow{2}{*}{ 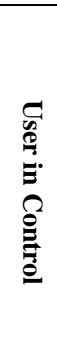 } & \multirow{2}{*}{ 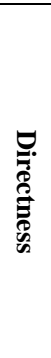 } & \multirow{2}{*}{ 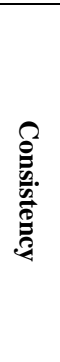 } & \multirow{2}{*}{ 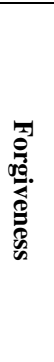 } & \multirow{2}{*}{ 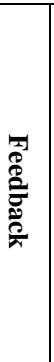 } & \multirow{2}{*}{ 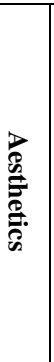 } & \multirow{2}{*}{ 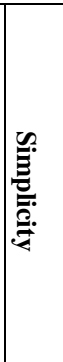 } & \multirow{2}{*}{\begin{tabular}{|c} 
Physical \\
\\
Type of \\
Pathological \\
Disorder
\end{tabular}} & \multirow{2}{*}{$\begin{array}{c}\text { Mental } \\
\text { Type of } \\
\text { Mental } \\
\text { Disorder }\end{array}$} & \multirow{2}{*}{ 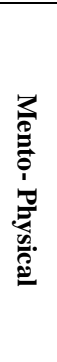 } & \\
\hline & & & & & & & & 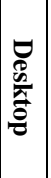 & $\bar{\sigma}$ & . & 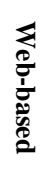 & 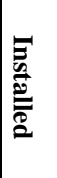 & 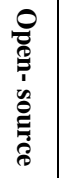 & 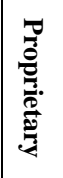 & & & & & & & & & & & \\
\hline Dexteria Dots $^{(13)}$ & & & $\checkmark$ & & & & $\checkmark$ & & $\checkmark$ & & & $\checkmark$ & & $\checkmark$ & $\mathrm{H}$ & $\mathrm{H}$ & M & $\mathrm{H}$ & $\mathrm{H}$ & $\mathrm{H}$ & $\mathrm{H}$ & & $\begin{array}{c}\text { visual tracking \& fine } \\
\text { motor skill, visual memory, } \\
\text { motor planning }\end{array}$ & & Constructivism \\
\hline Dexteria Dots $2^{(14)}$ & & & $\checkmark$ & $\checkmark$ & & & $\checkmark$ & & $\checkmark$ & & $\checkmark$ & & & $\checkmark$ & $\mathrm{H}$ & $\mathrm{H}$ & M & $\mathrm{L}$ & M & $\mathrm{H}$ & $\mathrm{H}$ & & $\begin{array}{c}\text { visual tracking \& fine } \\
\text { motor skill, visual memory, } \\
\text { motor planning }\end{array}$ & & Behaviorism \\
\hline $\begin{array}{l}\text { Physical Therapy } \\
\text { Home exercises }{ }^{(15)}\end{array}$ & & & $\checkmark$ & $\checkmark$ & & & $\checkmark$ & & $\checkmark$ & & & $\checkmark$ & $\checkmark$ & & M & M & M & M & M & M & $\mathrm{H}$ & $\begin{array}{l}\text { Fingers, Hand, Feet, Elbows, } \\
\text { Knees }\end{array}$ & & & Behaviorism \\
\hline $\begin{array}{l}\text { Physical Therapy } \\
\text { for Kids }{ }^{(16)}\end{array}$ & & & $\checkmark$ & & & & $\checkmark$ & & $\checkmark$ & & & $\checkmark$ & & $\checkmark$ & M & M & $\mathrm{H}$ & $\mathrm{L}$ & M & $\mathrm{H}$ & $\mathrm{H}$ & $\begin{array}{l}\text { Hands, Arms, Feet, Knees, } \\
\text { Elbows, Waist }\end{array}$ & & & Behaviorism \\
\hline $\begin{array}{c}\text { My Health Lounge } \\
\text { Physical } \\
\text { Therapy }^{\left({ }^{17)}\right.}\end{array}$ & $\checkmark$ & & $\checkmark$ & $\checkmark$ & $\checkmark$ & $\checkmark$ & $\checkmark$ & & $\checkmark$ & & $\checkmark$ & & $\checkmark$ & & M & M & M & $\mathrm{L}$ & M & $\mathrm{H}$ & $\mathrm{H}$ & $\begin{array}{l}\text { Legs, Knees, Elbows, Waist, } \\
\text { Spine }\end{array}$ & & & Behaviorism \\
\hline $\begin{array}{c}\text { Autism Learning } \\
\text { Games Camp } \\
\text { Discovery }^{(18)} \\
\end{array}$ & & & & $\checkmark$ & $\checkmark$ & & $\checkmark$ & & $\checkmark$ & & & $\checkmark$ & $\checkmark$ & & M & M & M & M & M & M & M & & Autism & & Behaviorism \\
\hline $\begin{array}{c}\text { Find me } \\
\text { (autism) }^{(19)}\end{array}$ & & & & $\checkmark$ & & & $\checkmark$ & & $\checkmark$ & & & $\checkmark$ & $\checkmark$ & & M & $\mathrm{L}$ & M & M & M & $\mathrm{H}$ & $\mathrm{H}$ & & Autism & & Behaviorism \\
\hline $\begin{array}{c}\text { BellyBio } \\
\text { Interactive } \\
\text { Breathing }{ }^{(20)}\end{array}$ & & $\checkmark$ & & $\checkmark$ & & & & & $\checkmark$ & & & $\checkmark$ & $\checkmark$ & & M & $\mathrm{H}$ & M & $\mathrm{L}$ & M & M & $\mathrm{H}$ & & $\begin{array}{c}\text { Breathing } \\
\text { and stress } \\
\text { management }\end{array}$ & & Behaviorism \\
\hline $\begin{array}{c}\text { Operation } \\
\text { Reach Out }^{(21)}\end{array}$ & & & & $\checkmark$ & & $\checkmark$ & & & $\checkmark$ & $\checkmark$ & $\checkmark$ & & $\checkmark$ & & M & $\mathrm{L}$ & $\mathrm{L}$ & M & M & $\mathrm{H}$ & $\mathrm{H}$ & & Depression & & Behaviorism \\
\hline $\begin{array}{c}\text { Deep Sleep } \\
\text { With Andrew } \\
\text { Johnson }^{(22)} \\
\end{array}$ & $\checkmark$ & & & & & $\checkmark$ & & & $\checkmark$ & & & $\checkmark$ & & $\checkmark$ & $\mathrm{L}$ & $\mathrm{H}$ & M & M & $\mathrm{H}$ & $\mathrm{H}$ & $\mathrm{H}$ & & Insomnia & & Behaviorism \\
\hline Optimism $^{(23)}$ & $\checkmark$ & & $\checkmark$ & $\checkmark$ & $\checkmark$ & & & $\checkmark$ & $\checkmark$ & & $\checkmark$ & & $\checkmark$ & & M & $\mathrm{L}$ & M & M & M & $\mathrm{H}$ & M & & Depression and Bipolar & & Behaviorism \\
\hline iSleep Easy ${ }^{(24)}$ & & & $\checkmark$ & & $\checkmark$ & & $\checkmark$ & & $\checkmark$ & & & $\checkmark$ & & $\checkmark$ & $\mathrm{L}$ & $\mathrm{H}$ & M & M & M & M & $\mathrm{H}$ & & Insomnia & & Behaviorism \\
\hline
\end{tabular}


ICIT 2015 The $7^{\text {th }}$ International Conference on Information Technology

doi:10.15849/icit.2015.0104 C ICIT 2015 (http://icit.zuj.edu.jo/ICIT15)

www.ptandot-helper.com (1) (2) (3)

www.dexteria.net ${ }^{(4)(12)(13)(14)}$

www.iot-session.com

www.angelfire.com/me/xutm ${ }^{(6)}$

www.pragmait.com ${ }^{(7)}$

www.askdrcovington.com ${ }^{(8)}$

www.doodletherapyapps.com ${ }^{(9)}$

www.apps.essare.net/app/ready-to-print ${ }^{(10)}$

www.sensationalbrain.com ${ }^{(11)}$

www.facebook.com/pages/PTGenie ${ }^{(15)}$

www.dfwapps3.com ${ }^{(16)}$

www.bluejayhealth.com ${ }^{(17)}$

www.campdiscoveryforautism.com ${ }^{(18}$

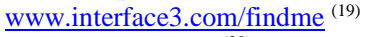

www.bellybio.com $^{(20)}$

www.militaryfamily.com/downloads/apps/military-suicide-prevention-

operation-reach-out/ $^{(21)}$

www.relaxationapps.com ${ }^{(22)}$

Www.findingoptimism.com ${ }^{(23)}$

www.meditationoasis.com/smartphone-apps/iphone-application-

support/isleep-easy-free-app-support ${ }^{(24)}$ 